\title{
PROEJASOCIAL: desenvolvimento e avaliação de uma rede social para ensino de matemática na educação de jovens e adultos
}

\author{
Leizer Fernandes Moraes ${ }^{1}$, Mara Rúbia de Souza Rodrigues Morais ${ }^{2}$ \\ ${ }^{1,2}$ Instituto Federal de Educação, Ciência e Tecnologia de Goiás (IFG) \\ 75.804-714 - Jataí - GO - Brasil \\ \{leizer.moraes, mara.morais\}@ifg.edu.br
}

\begin{abstract}
Mathematics education has the challenge to create new ways to teach and defeat the high reproach of students in this area. Social networks are an alternative, since they circulate in these virtual communities diverse materials containing mathematical concepts that can be explored by the teachers. This paper describes the development of a social network and its didactic contribution to teaching of mathematical equations in Adult Education class. The results showed that the use of this social network, inserted in a didactic sequence, contributed to the students' learning about mathematical equations.
\end{abstract}

Resumo. A educação matemática tem o desafio de criar novas formas de ensinar e combater a alta reprovação dos alunos nesta área. Redes sociais são uma alternativa, pois circulam nessas comunidades virtuais diversos materiais contendo conceitos matemáticos que podem ser explorados pelos professores. Este trabalho descreve o desenvolvimento de uma rede social e sua contribuição didática no ensino de equações matemáticas em uma turma de Educação de Jovens e Adultos. Os resultados evidenciaram que o uso dessa rede social, inserida em uma sequencia didática, contribuiu para a aprendizagem dos alunos sobre equações matemáticas.

\section{Introdução}

É importante aprender matemática em uma sociedade cada vez mais complexa, economicista e tecnológica - onde é possível verificar a presença desta área em vários setores e até mesmo relacionada a outras disciplinas. No entanto, os alunos ainda apresentam resistências à Matemática [Roque 2012] e dificuldades para compreender os seus conceitos, sobretudo em razão de sua linguagem algorítmica e formal [Roque 2012; Gómez-granell 2003].

É comum no cotidiano escolar ouvir dos alunos que a falta de tempo e o caráter teórico da matemática são as principais causas pelo seu rendimento abaixo do esperado nesta disciplina. Esses discursos refletem as considerações de Gómez-Granell [2003] quanto à necessidade de dar significado prático aos conceitos matemáticos, de Silva [2002] com relação ao tempo/escola e aos apontamentos de Roque [2012] quanto à direção social, dada historicamente, aos saberes práticos e teóricos da matemática. 
Quando Roque [2012, p.30] assinala que "a diferença entre o modo de fazer e de escrever está também muito presente na matemática, que parece estar escrita de trás para a frente", ela ilustra uma distância entre a linguagem matemática e a linguagem natural. Com isso, reforça a necessidade de pensarmos numa pedagogia que aproxime o aluno da matemática, e não o distancie dela. Convalida uma proposta pedagógica que, além de contribuir para a inserção social dos alunos, pode possibilitar $o$ desenvolvimento de habilidades necessárias para que eles compreendam essa linguagem e façam uso dela no ambiente externo à escola. Entre esses espaços de exterioridade ao contexto escolar, destacamos as redes sociais.

O espaço escolar, quando baseado somente na transmissão de conhecimentos, contraria os princípios da criatividade e deprime o processo de ensino e aprendizagem de Matemática [Oliveira et. al. 2016]. É essencial que tomemos as Tecnologias Digitais de Informação e Comunicação (TDIC) como recursos capazes de ampliar as capacidades da escola de oferecer aos alunos meios pelos quais eles possam buscar, na interação social, as respostas às suas dúvidas e as possibilidades de participarem de forma ativa do processo de ensino-aprendizagem [Levy 2011].

Com utilização de um espaço de colaboração, como redes sociais, o professor também é beneficiado no processo de ensino, pois tem a oportunidade de verificar aspectos que seriam difíceis de serem identificados em uma sala de aula, como a pesquisa sobre um assunto, a apresentação de uma opinião e o debate entre os alunos e professores a qualquer tempo [Lorenzo 2013].

Desta forma, este trabalho descreve o desenvolvimento de uma rede social denominada Proeja Social, e sua contribuição no processo de ensino de equações matemáticas, acoplada a uma sequencia didática (SD). Esse processo investigativo foi realizado durante uma pesquisa de mestrado, envolvendo 16 alunos e dois professores de uma turma de Educação Profissional com a Educação Básica na Modalidade de Educação de Jovens e Adultos (PROEJA) de uma instituição pública de educação na cidade de Jataí-GO.

Como trabalhos relacionados a este, podemos citar [Oliveira et. al. 2016], que descreve o processo de desenvolvimento e avaliação de uma Rede Social para ser utilizada como recurso didático na conscientização do uso responsável da água. Semelhante ao trabalho de Oliveira et. al. [2016], este artigo também aborda o processo de desenvolvimento a avaliação de uma rede social para fins didáticos, porém relacionada ao ensino de Matemática. Ainda como trabalho correlato, [Costa; Ferreira 2012] trata sobre a inserção das TDIC na educação, mais especificamente, sobre o uso da Rede Social Twitter no processo de ensino-aprendizagem da Matemática, apontando para a evolução do conhecimento dos alunos após o uso da rede social como recurso didático.

Enxergamos como principal diferencial deste trabalho, diante dos trabalhos relacionados, o processo de desenvolvimento e uso de uma Rede Social específica como recurso didático no ensino de matemática na modalidade de Educação de Jovens e Adultos. 


\section{Percurso metodológico}

O processo relatado neste artigo foi estruturado a partir da organização de uma sequência didática [Dolz; Noverraz; Schneuwly 2004] em interface com o desenvolvimento e aplicação de um produto com fins pedagógicos e caracterizado pela similaridade com as redes sociais. Tal percurso teve como propósito verificar se o uso de uma rede social, aplicada ao ensino de matemática por meio de uma SD, contribui para a aprendizagem desses conteúdos pelos alunos do primeiro ano do PROEJA.

A SD aplicada possui uma estrutura de base segmentada em (4) quatro partes (figura 1), levando em consideração a seguinte ordem: I - apresentação da situação: momento em que foi apresentado aos alunos o conteúdo a ser trabalhado na SD; II produção inicial: aplicação de uma avaliação para diagnosticar as dificuldades dos alunos com relação ao conteúdo a ser trabalhado em sala de aula; III - aplicação dos módulos: desenvolvimento das aulas; IV - produção final: última etapa da SD onde foi aplicada uma avaliação para verificar o desenvolvimento dos alunos após a etapa III.

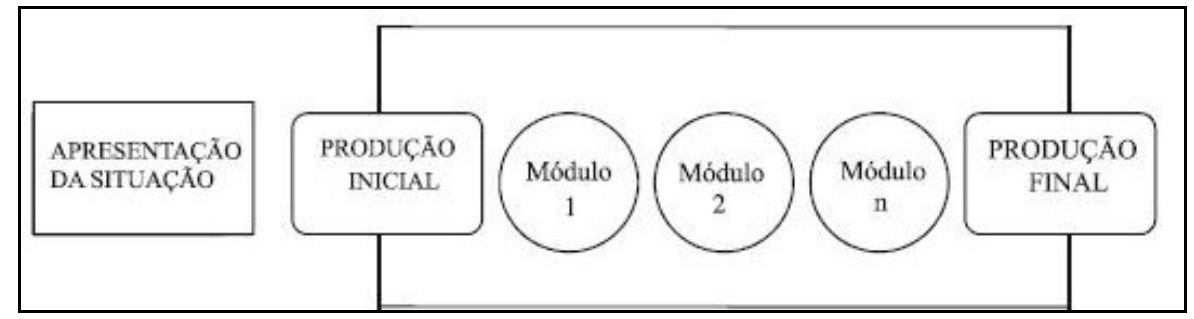

Figura 1 - Estrutura de base da Sequencia Didática aplicada

Fonte: Dolz, Noverraz e Schneuwly (2004).

Participaram da SD um professor de matemática e uma professora de língua portuguesa. O professor de Matemática atuou no ensino sintático-semântico do conteúdo de equações e a professora de Língua Portuguesa trabalhou o conceito de gêneros textuais, sobretudo o conceito de hipertexto e gênero digital [Marcuschi 2010].

A inserção da disciplina de Língua Portuguesa foi necessária para que os alunos pudessem compreender melhor os gêneros textuais presentes nas Redes Sociais, com destaque ao gênero cartum, principal material postado pelos professores na rede social descrita neste trabalho.

A fim de viabilizarmos o contato dos alunos com os conteúdos que circulam nas redes sociais, especialmente aqueles dotados de conceitos matemáticos, dispomos, além da sala de aula, de laboratório de informática com acesso à internet para que os alunos pudessem ter acesso aos conteúdos veiculados na rede social Facebook, especialmente, aos cartuns contendo conceitos matemáticos relacionados e apresentados em forma de equação. Esse ambiente também nos permitiu utilizar a rede social desenvolvida como instrumento didático à disposição dos professores. A SD foi composta por nove módulos, totalizando 14 aulas de matemática e 09 aulas de Língua Portuguesa, conforme apresentação da estrutura dos módulos da SD por meio da figura 2. 
VI Congresso Brasileiro de Informática na Educação (CBIE 2017)

Anais do XXIII Workshop de Informática na Escola (WIE 2017)
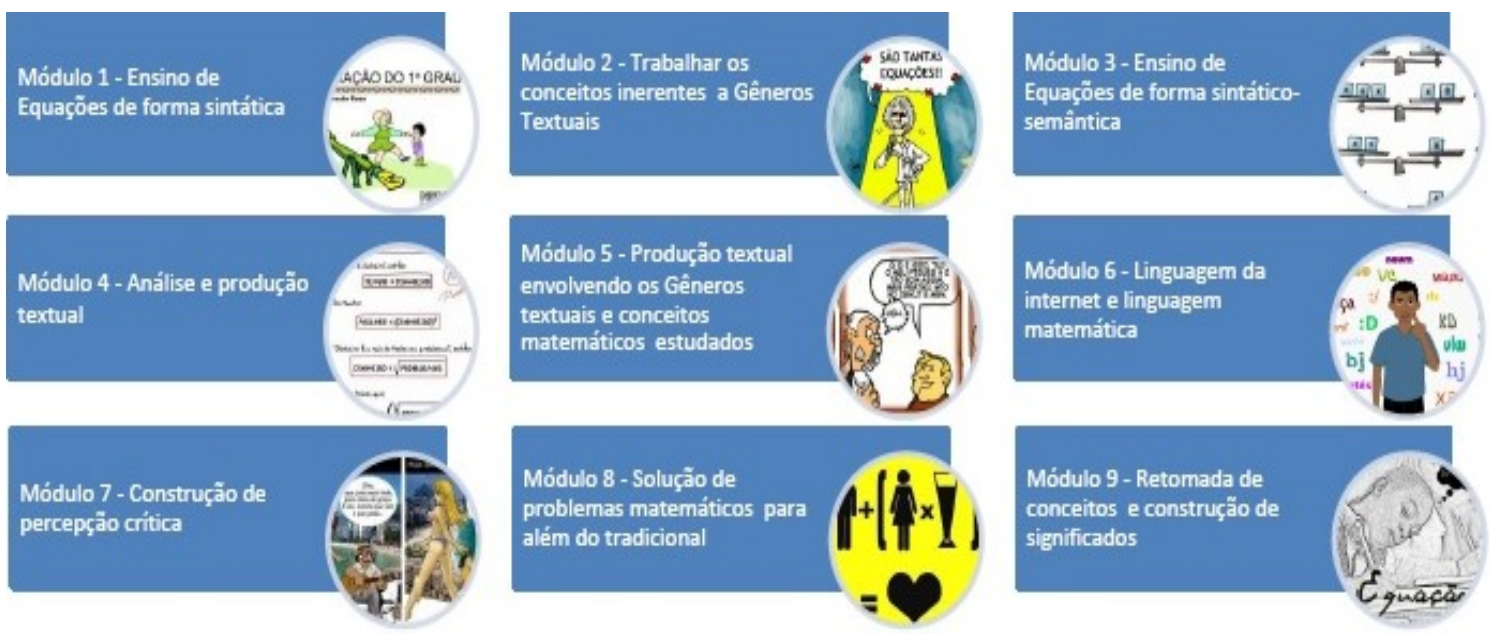

Figura 2 - Módulos da SD desenvolvida

O desenvolvimento do recurso didático (site ProejaSocial) foi realizado durante as aulas do módulo 01, momento em que não estava previsto ainda o uso de recursos didáticos digitais na SD. Após o desenvolvimento, o site foi disponibilizado aos professores e alunos por meio do endereço www.proejasocial.com.br.

O Proeja Social permite que professores postem conteúdos (texto ou imagem) e aos alunos é permitido comentar as postagens dos professores, conforme ilustrado nas figuras 03 e 04 . Cabe ressaltar que o Proeja Social não permite a postagem de conteúdos pelos alunos, apenas pelos professores. Aos alunos é permitido comentar as postagens dos professores e realizar a busca de postagens e comentários já inseridos na rede social.

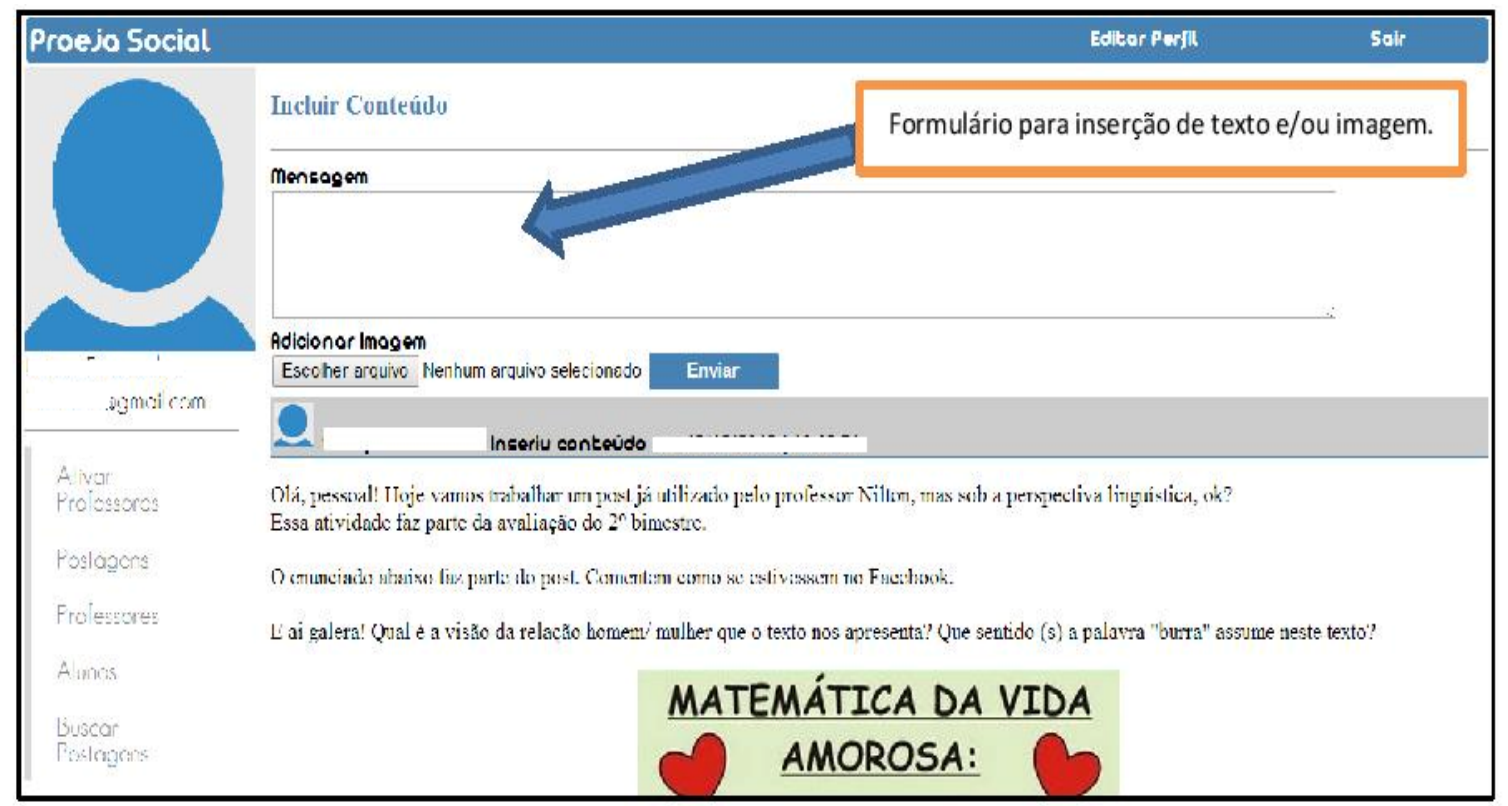

Figura 3 - Recorte da tela de perfil de um usuário do site Proeja Social do tipo "professor" 

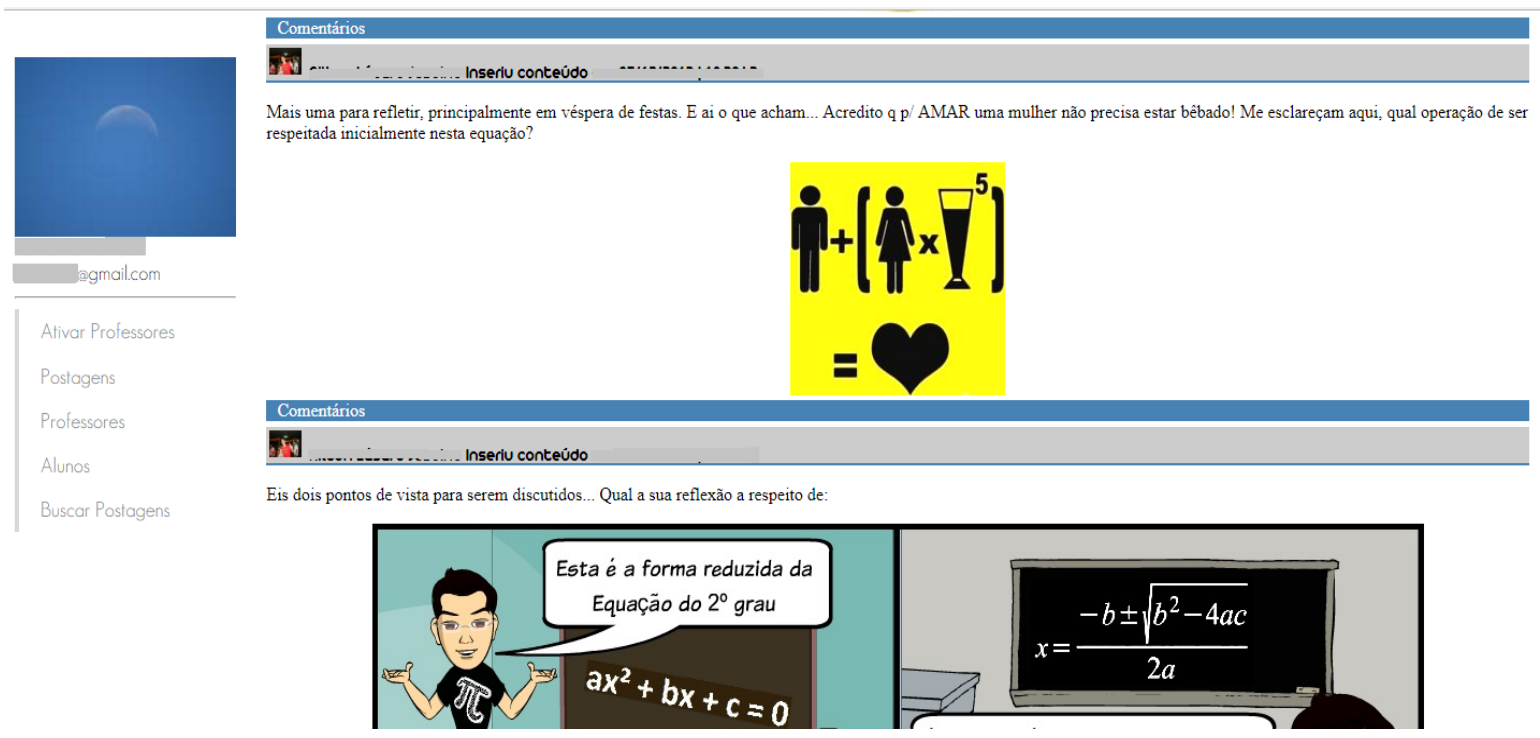

Figura 4 - Recorte da tela de perfil de um usuário do site Proeja Social contendo alguns cartuns postados pelos professores

Além disso, o site permite a pesquisa de postagens inseridas pelos professores, uma característica que o difere da principal rede social existente atualmente. Esta particularidade em relação a alguns sites disponíveis para esse fim no ciberespaço se tornaria difícil caso o professor utilizasse, por exemplo, o Facebook como ambiente educacional, visto que esse site de relacionamentos não permite tal "filtro". A busca de termos nos comentários dos alunos foi inserida com vistas a facilitar a análise das respostas dos alunos à determinada postagem do professor, configurando, portanto, como uma ação essencial ao trabalho de avaliação dos alunos pelo professor em relação às suas postagens.

Apesar dessa possibilidade, ela não é a única justificativa para o desenvolvimento de uma ferramenta própria com características de uma Rede Social a ser utilizada como instrumento didático, já que existem plataformas como o EDMODO, TEAMIE e SCHOOLOGY que se inscrevem nos moldes das redes sociais educacionais e permitem tal "filtro". Porém, por mais que se assemelhem ao site que foi desenvolvido, estas plataformas exigem passos mais complexos para sua utilização e algumas não têm versões em português.

Isto poderia inviabilizar a proposta de ensino de matemática utilizando redes sociais na turma pesquisada, dada a dificuldade encontrada por alguns alunos e professores quanto ao domínio de outras línguas e o uso de ferramentas digitais mais complexas.

Identificada essas dificuldades ainda no planejamento do processo de investigação, optamos por desenvolver o site Proeja Social com as mesmas características das redes sociais educacionais, mas que permitisse uma usabilidade maior dos alunos e professores do PROEJA. Com o intuito de validar a usabilidade do software, foi realizada uma aula teste utilizando o site Proeja Social antes de encerrar o primeiro módulo da SD. Nesta oportunidade observamos que o site desenvolvido já poderia ser utilizado como instrumento didático nos próximos módulos da SD. 


\section{Resultados e Discussões}

Ao término da SD, comparando as respostas dos alunos nas produções Inicial e Final, foram identificados avanços com relação à apropriação dos conceitos envolvendo equações matemáticas. Destacamos a evolução de $19 \%$ para $47 \%$ dos alunos que conseguiram dominar os fundamentos do conteúdo matemático trabalhado pelos professores com o uso da Rede Social desenvolvida para a turma.

Cabe ressaltar que as produções dos alunos consistiam em solucionar problemas envolvendo equações de primeiro e segundo grau onde os problemas a serem solucionados eram compostos por questões que utilizavam um enunciado tradicional (apenas a equação a ser solucionada utilizando a linguagem formal da matemática) e alguns problemas com o enunciado composto por um cartum, onde o aluno deveria compreender não só os conceitos e estrutura da equação matemática inserida nele, mas ter condições de fazer uma leitura adequada da equação presente naquele material.

As respostas dos alunos foram organizadas em categorias, quanto aos aspectos matemáticos coletados nas produções inicial e final, a saber: I - reconhecimento da matemática como elemento presente na formação dos cartuns trabalhados pelos professores; II - domínio dos fundamentos de equações e III - compreensão em sua totalidade da equação presente nos cartuns que foram publicados no Proeja Social.

O desenvolvimento dos alunos quanto à percepção dos conceitos matemáticos, o domínio dos fundamentos da matemática, sobretudo, em relação às equações de primeiro e segundo grau apresentou-se satisfatório, conforme apresentado na figura 5.
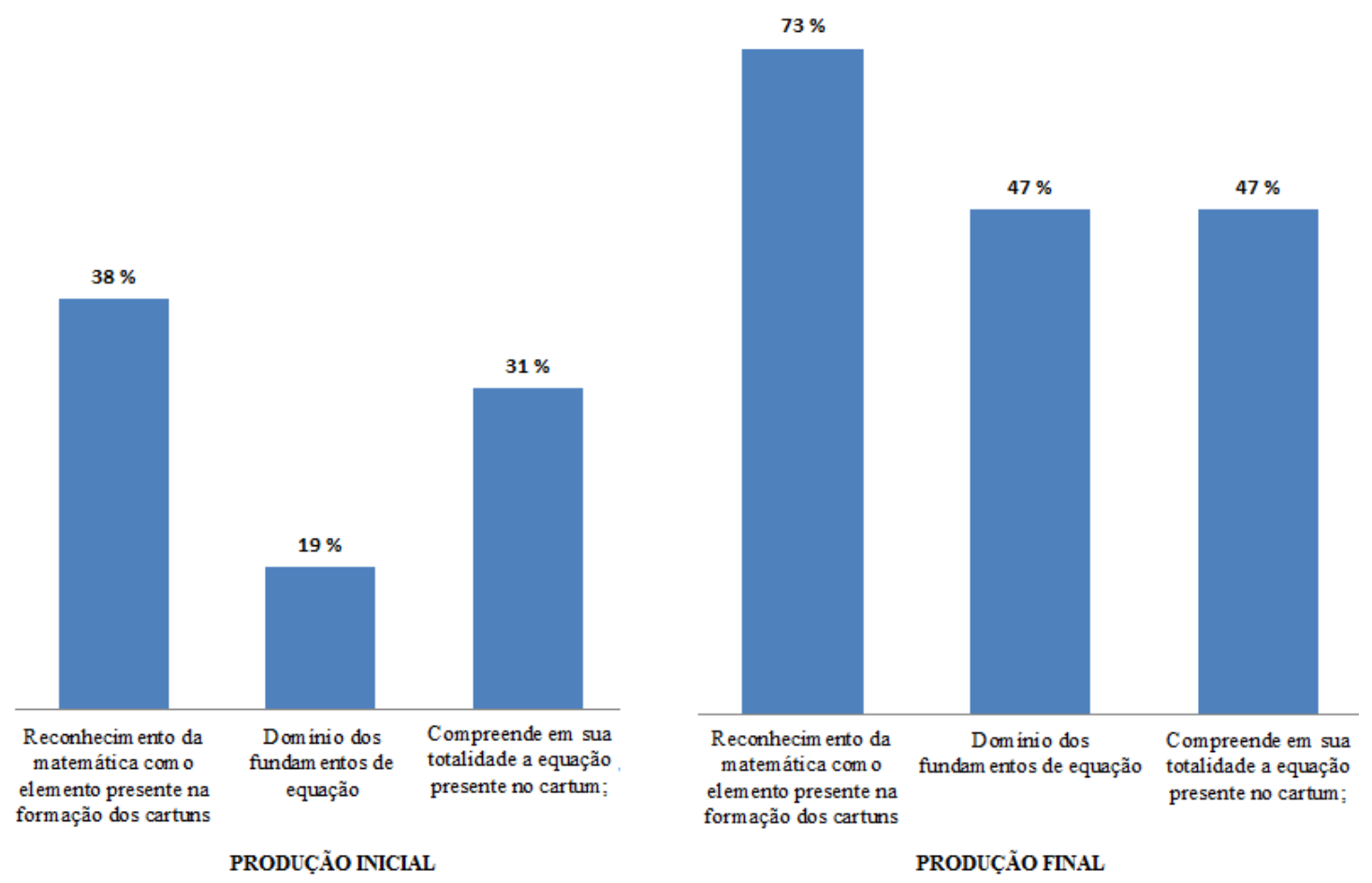

Figura 5 - Comparação do desempenho dos alunos quanto aos aspectos matemáticos identificados nas suas produções inicial e final 
Fica evidenciado que o uso do Proeja Social e, em especial, os cartuns postados pelos professores nesta plataforma e discutidos por meio dos comentários, contribuiu para que o número de alunos capazes de reconhecer a matemática "presente" nos cartuns saltasse de $38 \%$ na produção inicial dos alunos para $73 \%$ na produção final. Isso nos indica que o uso da tecnologia desenvolvida potencializou as capacidades de compreensão não só dos conceitos formais da matemática, mas também a capacidade dos alunos de fazer uma "leitura matemática" que vai além da formalidade que essa área carrega. Por meio da figura 5 é possível perceber então que em todos os aspectos estudados houve desenvolvimento dos alunos em relação à matemática.

Além da análise realizada sobre as produções inicial e final, alguns dados foram coletados por meio de uma entrevista estruturada [LAKATOS; MARCONI 2003] realizada com cada um dos discentes que participaram do experimento, com o objetivo de avaliar o uso do site Proeja Social no ensino de equações matemáticas. Cabe ressaltar que dos 16 alunos da turma investigada, 15 permaneceram no curso até o encerramento do semestre letivo e participaram da entrevista.

As entrevistas foram gravadas em áudio, transcritas e categorizadas conforme a regularidade das falas dos alunos. Algumas respostas foram vinculadas em mais de uma categoria e, por essa razão, existem perguntas em que a porcentagem de alunos supera os $100 \%$. Essa categorização bem como a porcentagem de respostas dos alunos em cada categoria é apresentada na tabela 1.

Tabela 1 - Regularidades encontradas nas respostas dos alunos sobre a utilização do site Proeja Social na SD para ensino de equações matemáticas

\begin{tabular}{|c|c|c|}
\hline Perguntas & Categoria de resposta & $\%$ \\
\hline $\begin{array}{l}\text { Você já estudou matemática } \\
\text { utilizando os materiais didáticos e } \\
\text { técnicas utilizados nesta } \\
\text { Sequência didática? Se a resposta } \\
\text { for não, o que você identificou de } \\
\text { diferença neste processo? }\end{array}$ & $\begin{array}{l}\text { - Responderam NÃO e atribuíram como } \\
\text { diferencial da SD o uso do Site PROEJA SOCIAL } \\
\text { - Responderam NÃO e citaram a facilidade de } \\
\text { assimilar os conceitos como um diferencial da SD } \\
\text { aplicada. } \\
\text { - Responderam NÃO e identificaram na SD a } \\
\text { possibilidade de aprendizagem enquanto outros } \\
\text { modelos estimulam a memorização. } \\
\text { - Respondeu SIM. }\end{array}$ & $\begin{array}{l}27 \% \\
7 \%\end{array}$ \\
\hline $\begin{array}{l}\text { Você conseguia relacionar a } \\
\text { matemática com o seu cotidiano } \\
\text { nas aulas de matemática que teve } \\
\text { antes de entrar no Proeja? }\end{array}$ & $\begin{array}{l}\text { - } \quad \text { Responderam NÃO. } \\
\text { - } \quad \text { Responderam SIM e associavam a compras ou } \\
\text { serviço. } \\
\text { - Respondeu SIM e atribuiu à SD a ampliação das } \\
\text { possibilidades de relacionar matemática ao seu } \\
\text { cotidiano. }\end{array}$ & $60 \%$ \\
\hline $\begin{array}{l}\text { Ao realizar a produção final dessa } \\
\text { sequencia didática, você teve } \\
\text { menos ou mais dificuldades em } \\
\text { comparação com a produção } \\
\text { Inicial realizada no início da SD? }\end{array}$ & $\begin{array}{l}\text { - Menos dificuldades e mencionam o SITE } \\
\text { PROEJA SOCIAL como fator que auxiliou na } \\
\text { aprendizagem. } \\
\text { - Respondeu que apresentou as mesmas } \\
\text { dificuldades } \\
\text { - Menos dificuldades e atribui às aulas que } \\
\text { compuseram os módulos da SD como fator que } \\
\text { auxiliou na construção do conhecimento necessário } \\
\text { para realizar a Produção Final com menos } \\
\text { dificuldades }\end{array}$ & $60 \%$ \\
\hline
\end{tabular}


VI Congresso Brasileiro de Informática na Educação (CBIE 2017)

Anais do XXIII Workshop de Informática na Escola (WIE 2017)

- Não soube responder ou não apresentou dificuldades em nenhuma produção.

- Responderam SIM e atribuíram o uso de imagens, cartuns e a prática como elementos que $27 \%$ facilitaram a aprendizagem.

- Responderam SIM e atribuíram ao uso do

Você acredita que o uso da rede social contribuiu para que você se apropriasse dos conceitos estudados? computador/site como fator importante no processo $27 \%$ de aquisição dos conceitos.

- Responderam SIM e atribuíram à facilidade de aprendizagem em detrimento da memorização - $27 \%$ presente nos módulos da SD.

- Responderam SIM e mencionaram a integração matemática/português como um dos fatores que $20 \%$ auxiliaram na aprendizagem

É possível afirmar que uma parte considerável dos alunos entendeu que seu conhecimento sobre equações foi ampliado após o uso da Rede Social na SD, visto que todos responderam que o seu uso contribuiu para que se apropriassem dos conceitos estudados. Além disso, $60 \%$ responderam que esse recurso foi o principal diferencial para que tivessem menos dificuldades na produção final da SD em comparação com a inicial.

Percebe-se, também, que os alunos atribuíram ao site desenvolvido algumas características positivas, qualificando-o como um recurso didático diferencial na própria aprendizagem.

\section{Considerações finais e apontamentos futuros}

Esta pesquisa partiu do pressuposto de que o uso de um instrumento didático com as mesmas características das Redes Sociais, associado a uma SD adaptada para o ensino de equações matemáticas, contribui para a apropriação desses conceitos pelos alunos de uma turma de Proeja em uma instituição de ensino pública na cidade de Jataí/GO. Da pesquisa, emergiram dados relevantes que nos auxiliaram a comprovar esse pressuposto, visto que eles apresentam um desenvolvimento considerável dos alunos no que tange à aprendizagem matemática e, sobretudo, na apropriação dos conceitos relacionados às equações matemáticas.

O estudo presta um serviço relevante para a educação matemática, que enfrenta grandes desafios, especialmente aqueles citados por [Roque 2012; Gómez-granell 2003; Gomes et. al. 2006], que, de maneira geral, são relacionados à necessidade de desmistificar nos alunos a ideia de que a matemática possui conteúdos inacessíveis e conceitos de difícil compreensão. Além disso, essa investigação nos revela o quanto a aplicação de novas propostas de ensino utilizando TDIC, com destaque às Redes Sociais, pode potencializar o ensino de matemática na educação básica.

Este estudo abre também a possibilidade para novas propostas de ensino de matemática permeado pela aplicação da Informática na Educação, transformando a sala de aula em espaços de construção e descobertas por meio das tecnologias e da interação social.

Acreditamos que uma investigação nesta linha possa contribuir para o desenvolvimento de novos recursos didáticos que, posteriormente, poderão ser apropriados para o aprimoramento do ensino de conceitos matemáticos. 
VI Congresso Brasileiro de Informática na Educação (CBIE 2017)

Anais do XXIII Workshop de Informática na Escola (WIE 2017)

\section{Referências}

Costa, A. M. S. N.; Ferreira. A. L. A. (2012). Redes Sociais na Educação: aprendizagem colaborativa no ensino de Matemática. In: Anais do $1^{\circ}$ Seminário Nacional de Inclusão Digital (SENID), Passo Fundo - RS. Disponível em: $<$ http://gepid.upf.br/senid/2012/anais/96235.pdf>. Acesso em: 23 mar. 2017.

Dolz, J.; Noverraz, M.; Schneuwly, B. (2004). Sequências didáticas para o oral e a escrita: apresentação de um procedimento. In: SCHNEULWY, B; DOLZ, J. et al. Gêneros orais e escritos na escola. Campinas: Mercado de Letras, p. 95-128.

Gomes, M. G. et al. (2006). “Obstáculos na aprendizagem matemática: identificação e busca de superação nos cursos de formação de professores das séries iniciais.

Gómez-granell, C. (2003). A aquisição da linguagem matemática: símbolo e significado. In: Teberosky, A.; Tolchinsky, A.. Além da alfabetização: a aprendizagem fonológica, ortográfica, textual e matemática. São Paulo: Ática, p.257-282.

Lakatos, E. M.; Marconi, M. de A. (2003). Fundamentos de Metodologia Científica. 5. ed. São Paulo: Atlas.

Levy, P. (2011). O que é o virtual? 2. ed. São Paulo: Editora 34, 160 p.

Lorenzo, E. M. (2013). A Utilização das Redes Sociais na Educação: A Importância das Redes Sociais na Educação. 3 ed. São Paulo: Clube de Autores,126p.

Marcuschi, L. A.; Xavier, A. C. (Org.). (2010). Hipertextos e gêneros digitais: novas formas de construção de sentidos. 3. ed. São Paulo: Cortez.

Oliveira, A. C. F. M. et. al. (2016). Processo de Desenvolvimento e Avaliação de uma Rede Social para conscientização acerca do consume da Água. In: Anais do XXII Workshop de Informática na Escola (WIE 2016), Uberlândia - MG. p. 933-942. Disponível em: <http://br-ie.org/pub/index.php/wie/article/view/6637>. Acesso em: 23 mar. 2017.

Oliveira, A. N. et al. (2016). O Uso das Tecnologias Digitais no Apoio a Construção do Conhecimento Matemático. In: Anais do XXII Workshop de Informática na Escola, Uberlândia - MG. p. 191-200. Disponível em: <http://www.brie.org/pub/index.php/wie/article/view/6616>. Acesso em: 23 mar. 2017.

Roque, T. (2012). História da matemática: Uma visão crítica, desfazendo mitos e lendas. Rio de Janeiro: Zahar, 512 p.

Silva, B. D. (2002). A inserção das tecnologias de informação e comunicação no currículo: Repercussões e exigências na profissionalidade docente In: Moreira, A. F. B. et al (Org.). Currículo, Práticas Pedagógicas e Identidades. Porto: Porto Editora, 160 p. Revisão: Maria Cecília Gomes Barbosa Moreira. 